\title{
Charting the Next Decade for Value Sensitive Design
}

\author{
Batya Friedman \\ University of Washington \\ Seattle, WA, USA 98195-2840 \\ batya@uw.edu
}

\author{
Catholijn Jonker \\ Delft University of Technology \\ 2628 CD Delft, Netherlands \\ C.M.Jonker@tudelft.nl
}

\author{
David G. Hendry \\ University of Washington \\ Seattle, WA, USA 98195-2840 \\ dhendry@uw.edu
}

Jeroen van den Hoven
Delft University of Technology
2628 BX Delft, Netherlands
M.J.vandenHoven@tudelft.nl

\author{
Alina Huldtgren \\ Eindhoven University of \\ Technology \\ 5600 MB Eindhoven, Netherlands \\ a.huldtgren@tue.nl \\ Aimee van Wynsberghe \\ University of Twente \\ Enschede, Netherlands, 7500AE \\ a.1.vanwynsberghe@utwente.nl
}

\begin{abstract}
In the 2010's it is widely recognized by computer and information scientists, social scientists, designers, and philosophers of technology that the design of information systems is not value neutral $[5-8,11]$. Rather, such systems are value laden in part because societal values are major factors in shaping systems, and at the same time the design of the technology reinforces, restructures or uproots societal value structures. Of the many theories and methods to design for this phenomenon one continues to gain traction for its systematic and overarching consideration of values in the design process: Value Sensitive Design (VSD) [5-7]. The aim of this multidisciplinary workshop is to bring together scholars and practitioners interested in ways values can be made to bear upon design and to help continue to build a community by sharing experiences, insights, and criticism.
\end{abstract}

\section{Author Keywords}

Value Sensitive Design, Human Computer Interaction, Technology and Human Values, Applied Ethics.

\section{ACM Classification Keywords}

K.4.1 [Computers and society]: Public policy issues Ethics.

\section{WORKSHOP OBJECTIVES}

The literature and projects dedicated to and exploring both methodological and theoretical issues of value sensitive design (VSD) have grown exponentially in recent years. Despite the wide-scale uptake of the VSD approach, however, as one would expect for an approach that touches such basic human questions and continues to evolve, methodological and theoretical questions and controversies remain [1]. To that end, a forum is needed to bring researchers and designers together to grow a cohesive

Copyright $(C) 2015$ is held by the author(s). Publication rights licensed to Aarhus University and ACM

5th Decennial Aarhus Conference on Critical Alternatives

August 17 - 21, 2015, Aarhus Denmark

DOI: http://dx.doi.org/10.7146/aahcc.v1i1.21619 community and chart next steps for broadening the scope, methods, and application of VSD. This workshop builds on previous work by the organizers and others to achieve the following objectives:

- Critically discuss experiences and case studies of VSD with a multidisciplinary group of researchers.

- Explore differences in VSD methods for short versus long-term projects.

- Discuss and critique various adaptations and appropriations of VSD.

- Identify open questions and grand challenges for the next decade of research and design work in VSD.

- Build a network of support among both novice and expert researchers and designers in VSD.

- Discuss future directions, obstacles and opportunities for collaboration among the international community.

\section{SIGNIFICANCE OF THE WORKSHOP}

There are many reasons why a workshop organized around charting future directions for value sensitive deign is timely and significant. For one, VSD has been a vibrant and developing approach for 20 years with an extensive body of work $[1,3,5-8,10,13,14]$ : the ACM Digital Library shows an increase in papers that mention "human values" from 20 in 2000 to 113 in 2010 [1]. Despite this increase in interest and scholarly productivity, the community of scholars, designers, and researchers working with VSD is rather dispersed; in fact, many of the researchers engaging with this approach have not met the others in person. It is time to bring these individuals together to develop a common research agenda and repository that novice and experts can access and build upon. This workshop will be the first event of its kind devoted to the analysis, development and critique of VSD as a theory, methods, and approach to design.

In addition, this workshop will facilitate a proactive meeting in which researchers can engage in the relationship between VSD and emerging technologies. Society is on the cusp of a radical change in computing, from personal computing to large-scale networked computing (e.g. the 
Internet of Things, ubiquitous computing, etc.), at work, at home and in public spaces. Robotics [13], multi-lifespan information systems [6], and big data science [2] are but three areas in which researchers have targeted the significant impact that VSD can have on the design process, not only to ensure value sensitive functionality, but also to inform policy makers and to increase the adoption of technologies with positive potential. Although VSD has been identified as a constructive tool for the future design of these and other technologies, there are still pressing questions that must be addressed to further this work. Now is a crucial moment for establishing a network of researchers for assistance, support, feedback and collaboration.

Perhaps the most compelling reason for a workshop to further a value sensitive design approach has to do with the speed at which emerging technologies are developing and the complexity of addressing related societal and ethical issues [4, 8, 10-13]. VSD shows great novelty and scope in that it allows for an approach to design that invites contributions and reflections from philosophers and ethicists alongside those of social scientists, behavioral scientists, computer scientists, and designers. VSD resists the tendency to only retrospectively assess or evaluate technologies, and instead invites proactive value analyses in conjunction with technology design and development. Rarely have multiple disciplines been engaged in such a collaborative feat. We believe that given this spirit of partnership, spanning multiple disciplines and contexts of research, researchers ought to have the opportunity to come together to meet, discuss and pave the way forward for VSD. Several Research Councils in Europe have embraced the conception of designing for moral values as a way of doing applied ethics of technology. For example, the Dutch Research Council initiated a research program entitled Responsible Innovation in 2007 that made the VSD paradigm central to its approach to ethics of technology. In turn, the European Commission - inspired by this approach - has made designing for values part of its large new 80 billion Euro R\&D framework Horizon 2020 [9].

\section{BENEFITS OF THE WORKSHOP}

In addressing the aims and objectives listed above, this workshop has many benefits including but not limited to:

- Building an international, multidisciplinary community of VSD researchers involving novice and expert scholars from a variety of disciplines (e.g. artificial intelligence, computer science and engineering, design, ethics, human-computer interaction, information science, philosophy, sociology)

- Helping disseminate and further evolve VSD method, including methods for: discovering, articulating and communicating values and value considerations; engaging with emergent values; addressing value tensions; evaluating resulting technologies; and selecting among and combining diverse methods

- $\quad$ Revealing areas and opportunities for future directions

- $\quad$ Paving the way for large-scale applications of VSD across institutions and countries.

\section{OVERVIEW OF THE WORKSHOP}

\section{Participants and recruitment strategy}

The intended workshop size is 15-20 people to ensure a fruitful discussion and to develop a thoughtful action plan for bringing VSD to a larger scale that can begin to account for identified challenges of the emerging networked society. We aim for a multidisciplinary group of workshop participants to shed light on the coming challenges from different perspectives. In particular, we welcome researchers in artificial intelligence, computer science and related engineering fields, data science, design, e-social sciences, ethics, human-computer interaction, intelligent systems, philosophy, and sociology. Recruitment will be carried out through our personal network of VSD scholars as well as by disseminating the call for participation via mailing lists and relevant websites (see 3.2).

\section{Workshop Planning}

Pre-workshop: An outline of the workshop's topic, goals, and a call for participation will be disseminated via various mailing lists

(e.g.CHI-

ANNOUNCEMENTS@1istserv.acm.org;

announcements.eu.nordichi@maillist.au.dk;

valuesindesign@

tudelft.nl; anthrodesign@yahoogroups.com; and others); websites (www.vsdesign.org; ethicsandtechnology.eu and others); and social outlets via a workshop's Twitter account.

Prospective participants are invited to submit short papers including design case studies, critical reflections, and visionary perspectives on VSD. At least one author of each accepted paper or project will be required to attend the workshop. Submissions will undergo juried review by the workshop organizers and international experts in the field. Authors will have an opportunity for revision based on the reviews. Revised papers will be shared with all participants in advance of the workshop to familiarize everyone with the case studies and diverse views on the topic.

\section{One-day Workshop: Agenda and Discussion Topics}

(0.5 hour) Welcome and plan for the day.

(0.5 hour) Introductions.

(2.0 hours) Morning Session on sharing VSD projects, challenges and best practices with focus on the variety of uses and adaptations and the particular goals of this workshop. Key questions: What does VSD mean to different disciplines? How has VSD been used to date? What are some of the paradigmatic case studies that illustrate that utility and benefits of VSD? What are some of the key methods or methodological commitments? What 
common issues arise across the cases? What are the characteristics of successful case studies? What are the characteristics of less successful case studies? How do the cases help us to better understand the strengths and weaknesses of the VSD approach?

\section{(1.5 hours) Lunch Break.}

(1 hour) Brainstorming session on Grand Challenges for VSD. Key questions: Looking forward, what contexts of study might be most relevant to pursue? What problems should VSD target? What types of technology should VSD target? What kinds of researchers might act as part of the VSD team or as a values advocate? What would be a good set of the important questions or grand challenges for value sensitive design to take up in the coming decade?

(30 min.) Synthesizing grand challenges for VSD from brainstorming.

(30 min.) Brainstorming community activities (e.g., special journal issue, edited volumes, VSD online bibliography, VSD pedagogy).

(30 min.) Practical next steps. Discuss dissemination of workshop results, next activities, and future directions. Key questions: How can workshop participants make use of the workshop results in their own work? How can workshop participants spread their knowledge of VSD? At which conferences and forums might the participants try to reconvene?

Post-workshop: Papers and projects presented at the workshops, as well additional resources identified and created through workshop discussion and group activities will be collected and made available online through a wikibased website/VSD repository.

After the workshop, participants will be invited to submit extended versions of their work for inclusion in a special issue of the Journal of Ethics and Information Technology. We will also maintain a VSD mailing list to allow for future workshops or a VSD conference series to be organized.

\section{WORKSHOP ORGANIZERS}

Batya Friedman, $\mathrm{PhD}$, is a Professor in the Information School, Adjunct Professor in the Department of Computer Science, and Adjunct Professor in the Department of Human-Centered Design and Engineering at the University of Washington where she co-directs the Value Sensitive Design Research Lab. She pioneered value sensitive design and continues to explore new theory and methods as well as open questions within this approach.

David G. Hendry, PhD. is an Associate Professor in the Information School at the University of Washington where he co-directs the Value Sensitive Design Research Lab. He has applied and extended value sensitive design in a variety of domains and populations including working with homeless young people and with bringing value sensitive design thinking into technical education at the undergraduate and graduate level.

Alina Huldtgren, $\mathrm{PhD}$, is an Assistant Professor of Human-Computer Interaction at the School of Innovation Sciences at Eindhoven University of Technology. Her research concentrates on user-centered and value sensitive design of human-technology interfaces for healthcare, aging well and digital augmentation of public spaces. She has previously organized two workshops on values in design at the INTERACT and CHI conferences.

Catholijn Jonker, PhD, is head of the Design Engineering department of the Faculty of Industrial Design and member of the Interactive Intelligence Group of the INSY department of the Faculty of EEMCS. Her work addresses cognitive processes and concepts such as trust, negotiation, teamwork and the dynamics of individual agents and organizations. In her research she adopted a value-sensitive approach, in particular, towards intelligent agents that can interact with their users in value-conflicting situations when meta-values no longer solve the situation.

Jeroen van den Hoven, $\mathrm{PhD}$, is full professor of Ethics at Delft University of Technology. He is Head of Department of the Department of Values, Technology and Innovation. His research is concerned with ethical issues in new technology. He is Editor in Chief of Ethics and Information Technology (Springer) and has advised Dutch government and EU in different roles concerning ethics of information and communication technology and responsible innovation.

Aimee van Wynsberghe, $\mathrm{PhD}$, is an Assistant Professor in Ethics of Technology at the University of Twente, the Netherlands. With a background in applied ethics, her research concentrates on the normative foundations for value sensitive design and its application to robotics, healthcare technologies and other ICT.

\section{ACKNOWLEDGMENTS}

We thank Alan Borning who provided comments on this workshop proposal.

\section{REFERENCES}

1. Borning, A., and Muller, M. 2012. Next steps for value sensitive design. In Proceedings of the ACM SIGCHI Conference on Human Factors in Computing Systems (CHI'12), 1125-1134.

2. boyd, d. and Crawford, K. 2011. Six provocations for big data. A decade in Internet time: Symposium on the Dynamics of the Internet and Society. Available at SSRN: http://dx.doi.org/10.2139/ssrn.1926431

3. Davis, J., and Nathan, L.P. 2014. Value Sensitive Design: Applications, adaptations, and critiques. In Handbook of Ethics, Values, and Technological Design 2014, Springer, pp 1-26. 
4. Detweiler, C.A., Dechesne, F., Hindriks, K. V., and Jonker, C. M. 2012. Ambient intelligence implies responsibility. In Ambient Intelligence and Smart Environments, Ebook. Volume 12: Agents and Ambient Intelligence, $33-61$.

5. Friedman, B., Kahn, P. H., Borning, A., and Huldtgren, A. 2013. Value Sensitive Design and information systems. Early engagement and new technologies: In Opening up the Laboratory. Doorn, N., Schuurbiers, D., van de Poel, I., Gorman, M.E. (Eds.). Springer Netherlands, 55-95. (Reprinted from Friedman, B., Kahn, P. H., Jr., and Borning, A. (2006). Value Sensitive Design and Information Systems. In P. Zhang and D. Galletta (eds.), Human-computer interaction in management information systems: Foundations (pp. 348-372). Armonk, NY: M. E.Sharpe.).

6. Friedman, B. and Nathan, L.P. 2010. Multi-lifespan information system design: a research initiative for the HCI community. In Proceedings of the SIGCHI Conference on Human Factors in Computing Systems. ACM, 2243-2246.

7. Friedman, B.. 1996. Value-sensitive design. Interactions 3(6), 16-23.

8. Hoven van den, J., Van de Poel, I., and Vermaas, P. E. Handbook of ethics, values and technological design. Available at Springer Link: http://link.springer.com/ referencework/10.1007\%2F978-94-007-6994-6.

9. Hoven van den, J. 2012. Brussels. Available at: http://ec.europa.eu/research/science-society/document _library/pdf_06/options-for-strengthening_en.pdf.

10. Hoven van den, J., Helbing, D., Pedreschi, D., Domingo-Ferrer, J., Gianotti, F., and Christen, M. (2012). FuturICT-The road towards ethical ICT. arXiv preprint arXiv: 1210.8181.

11. Mander-Huits, N., and Zimmer, M.. 2009. Values and pragmatic action: The challenges of introducing ethical intelligence in technical design communities.

International Review of Information Ethics 10(2), 3745.

12. Stahl, B. C., Heersmink, R., Goujon, P., Flick, C., van den Hoven, J., Wakunuma, K., and Rader, M. (2010). Issues, concepts and methods relating to the identification of the ethics of emerging ICTs. Available at:

http://www.academia.edu/432392/Issues_Concepts_an d_Methods_Relating_to_the_Identification_of_the_Eth ics_of_Emerging_ICTs.

13. van Wynsberghe, A.. 2013. Designing robots for care: Care centered value-sensitive design. Science and engineering ethics 19(2), 407-433.

14. Yoo, D. Huldtgren, H., Woelfer, J.P., Hendry, D.G., and Friedman, B.. 2013. A Value Sensitive Action-
Reflection Model: Evolving a co-design space with stakeholder and designer prompts. In Proceedings of the ACM SIGCHI Conference on Human Factors in Computing Systems (CHI '13), 419-428. 